\title{
Costs associated with management of non-communicable diseases in the Arab Region: a scoping review
}

\author{
Shadi Saleh ${ }^{1}$, Amena El \\ Harakeh $^{1}$, Maysa Baroud ${ }^{2}$, \\ Najah Zeineddine ${ }^{1}$, Angie \\ Farah $^{1}$, Abla Mehio Sibai ${ }^{3}$ \\ ${ }^{1}$ Department of Health Management \\ and Policy, Faculty of Health Sciences, \\ American University of Beirut, Beirut, \\ Lebanon \\ ${ }^{2}$ Refugee Research and Policy Program, \\ Issam Fares Institute for Public Policy \\ and International Affairs. American \\ University of Beirut, Beirut, Lebanon \\ ${ }^{3}$ Department of Epidemiology and \\ Population Health, Faculty of Health \\ Sciences, American University of \\ Beirut, Beirut, Lebanon
}

Background Global mortality rates resulting from non-communicable diseases (NCDs) are reaching alarming levels, especially in low- and middle-income countries, imposing a considerable burden on individuals and health systems as a whole. This scoping review aims at synthesizing the existing literature evaluating the cost associated with the management and treatment of major NCDs across all Arab countries; at evaluating the quality of these studies; and at identifying the gap in existing literature.

Methods A systematic search was conducted using Medline electronic database to retrieve articles evaluating costs associated with management of NCDs in Arab countries, published in English between January 2000 and April 2016. 55 studies met the eligibility criteria and were independently screened by two reviewers who extracted/calculated the following information: country, theme (management of NCD, treatment/medication, or procedure), study design, setting, population/sample size, publication year, year for cost data cost conversion (US\$), costing approach, costing perspective, type of costs, source of information and quality evaluation using the Newcastle-Ottawa Scale (NOS).

Results The reviewed articles covered 16 countries in the Arab region. Most of the studies were observational with a retrospective or prospective design, with a relatively low to very low quality score. Our synthesis revealed that NCDs' management costs in the Arab region are high; however, there is a large variation in the methods used to quantify the costs of NCDs in these countries, making it difficult to conduct any type of comparisons.

Conclusions The findings revealed that data on the direct costs of NCDs remains limited by the paucity of this type of evidence and the generally low quality of studies published in this area. There is a need for future studies, of improved and harmonized methodology, as such evidence is key for decision-makers and directs health care planning.

\section{Correspondence to:}

\section{Dr. Shadi Saleh, PhD}

Department of Health Management and Policy

Faculty of Health Sciences

American University of Beirut

Bliss Street

Beirut

Lebanon

ss117@aub.edu.lb
Global mortality rates resulting from non-communicable diseases (NCDs) are reaching alarming levels with an increase from below 8 million between 1990 and 2010 to 34.5 million during year 2010 [1]. This figure is estimated to reach 52 million by 2030 [2,3]. Notably, low- and middle-income countries (LMICs) witnessed highest percentage increase of NCDs deaths with an expected average of 7 out of every 10 deaths occurring in developing countries by 2020 [4]. Eighty two percent of these deaths are caused by four major NCDs, namely cardiovascular diseases, chronic respiratory diseases (asthma and chronic obstructive pulmonary disease in particular), cancer, and diabetes [5-7]. Consistent with global trend, the Arab region was witnessing an increasing NCDs burden [8]. In Lebanon, 85\% of deaths are attributed to NCDs [9,10], while in Morocco 
and Kuwait, NCDs account for $75 \%$ and $73 \%$ of deaths, respectively [11,12]. Furthermore, while deaths caused by infectious diseases are declining in the West, some countries in the region still carry a double burden of disease like Sudan, where 34\% of deaths are attributable to NCDs, and 53\% still result from communicable diseases $[12,13]$. The latter challenge of dealing with multiple diseases is intensified by several factors: limited human and financial resources, weak surveillance system, limited access to health care services and lack of financial protection in terms of insurance or public funding [14].

Worldwide, the rising burden of death and disability attributed to NCDs threatens the functionality and effectiveness of the health sector and imposes risks on economic stability and development of societies $[15,16]$. In several developed and developing countries, health costs and productivity loss associated with management of diabetes alone represent a significant share of gross domestic product (GDP), reaching 1\% share from the US economy [17]. Economists are expressing major concerns about the long-term macroeconomic impact of NCDs on capital accumulation and GDP worldwide, with most severe consequences likely to be felt by developing countries [18]. In fact, it is estimated that NCDs costs will reach more than US $\$ 30$ trillion in the coming two decades [19] further challenging the ability of health care systems to cope with these rising costs, especially in resource-scarce countries [18].

Considerable literature exists on economic evaluation and costs associated with NCDs in different regions worldwide, mostly in high-income countries (HICs) [20-23]. However, to date, no such studies exist in LMICs [4,24-27] and minimal effort was undertaken to synthesize and analyze current evidence addressing this issue in a comprehensive review [28-30]. Additionally, there has not been any attempt to collate and review relevant literature and evaluate the quality of existing studies on NCDs' cost in the Arab region. This study aims to identify and synthesize available published evidence evaluating the cost associated with management and treatment of major NCDs across all Arab countries; to appraise critically these studies' quality; and to identify the gap in existing literature. This study's findings will aid in building a profile of the financial burden of NCDs in the Arab region, which would support and direct health care planning and future health research.

\section{METHODS}

\section{Search strategy and inclusion criteria}

A systematic search was conducted using Medline electronic database to identify and retrieve articles evaluating the cost associated with management of NCDs in all 22 Arab countries; namely: Algeria, Bahrain, Comoros, Djibouti, Egypt, Iraq, Jordan, Kuwait, Lebanon, Libya, Mauritania, Morocco, Oman, Palestine, Qatar, Saudi Arabia, Somalia, Sudan, Syria, Tunisia, United Arab Emirates and Yemen. Based on their global economic burden on governments and populations,

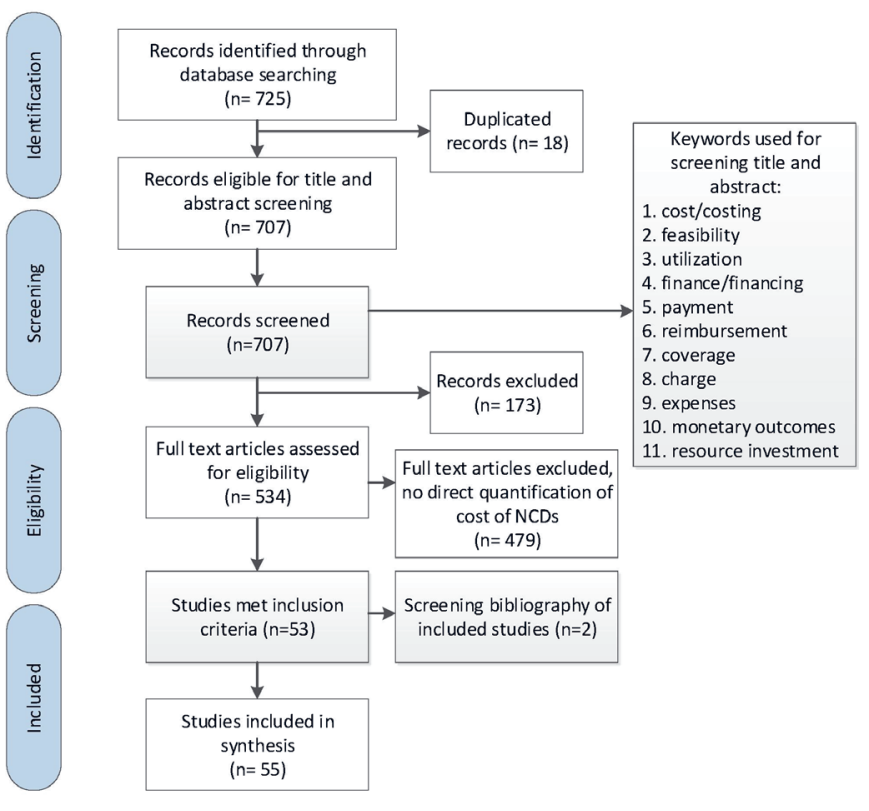

Figure 1. Flowchart of articles identified, included and excluded. the following NCDs were selected: cardiovascular diseases, cancer, chronic respiratory diseases and diabetes [31]. Only papers published in English between January 2000 and April 2016 inclusive were included. The complete search strategy applied in this review is available in Appendix S1 of Online Supplementary Document, and key inclusion and exclusion criteria are presented in Figure 1. The search strategy used MeSH terms and keywords relative to each of the four NCDs, their risk factors and costing including: Tobacco, Nutrition/ Diet, Alcohol and Substance Abuse, Physical Inactivity, Hypertension, Cholesterol, Hyperlipidemia, Metabolic Syndrome, Salt and Sodium Intake, Diabetes, Cardiovascular disease, Cancer, Chronic Lung Dysfunction, Asthma, COPD, Renal Dysfunction, and Chronic Diseases, Health Care Costs, Health Expenditure, Health Resources, Insurance, Reimbursement, Fees, Charges, Feasibility Studies and Cost Benefit Analysis. The terms were combined with each of the 22 countries in the Arab region. Retrieved articles were screened and reviewed to assess their eligibility based on their content 
and study population. A total of 725 papers were identified to fit the initial search criteria. After removing duplicates, 707 papers remained for further screening.

\section{Study selection}

Titles and abstracts of the initially identified articles were screened by two independent reviewers to assess whether they fulfill the selection criteria using keywords including cost/costing, feasibility, utilization, finance/financing, payment, reimbursement, coverage and charge, expenses, monetary outcomes and resource investment. Articles not including any of the above-mentioned keywords in the title or abstract were excluded. Hence, 534 articles were identified for full text review and were assessed by the two reviewers for relevance with regard to the research topic. Only those articles that provided direct quantification of costs associated with NCDs, their treatment, management, or risk factors within the target countries were included. Studies conducted outside of Arab region were excluded. Any disagreement between the two reviewers was resolved by discussion and consensus or through consultation with a third reviewer when needed. The identified eligible articles accounted for a total of 55 articles, tackling the issue of NCDs' costs within at least one of the Arab countries.

\section{Data abstraction}

Data was extracted from full texts included in this review using a data collection form composed of the following criteria (Table 1):

- Country - based on study location;

- Category - based on main theme/topic addressed: management of the NCD, treatment/medication, or procedure;

- Study design - classified as cross-sectional, cohort, review, or systematic review/meta-analysis;

- Setting - described as being a health system, cases from primary healthcare center, hospital, or clinic (private vs. public):

- Population/Sample size;

- Year of publication;

- Year for cost data;

- Costing approach - classified as bottom up or top down;

- Costing perspective - classified as societal, governmental, provider or patient;

- Type of costs - classified as direct medical, indirect medical and indirect;

- Source of information - classified as survey, medical record, health information survey or electronic database

The findings are presented by type of NCD. US $\$$ were used when assessing economic costs across all studies to enhance comparability. Other reported local currencies were converted to US $\$$ based on the exchange rate specified by the corresponding study. When exchange rate was not mentioned, conversion to US\$ was performed using the conversion rate specific to the year of publication of the study.

\section{Quality evaluation}

The quality of included cross-sectional, case-control and cohort studies was evaluated using the Newcastle-Ottawa Scale (NOS), which is based on three domains: selection, comparability and exposure [87]. A maximum of one star can be awarded to each question in the selection category and one star to each question included in the exposure category, while a maximum of two stars can be awarded to a single question in the comparability section. For each study, a quality score is then generated by adding up the number of stars given and would not exceed 9 stars. The modified version of the NOS used for descriptive and cross-sectional studies was adopted from the systematic review conducted by Jaspers et al (2015) [88].

\section{RESULTS}

We initially identified 725 potentially eligible references published between 2000 and 2016 (Figure 1). Of those, and after title and abstract and full text screenings, 55 studies met the inclusion criteria and were thoroughly described in the review. 


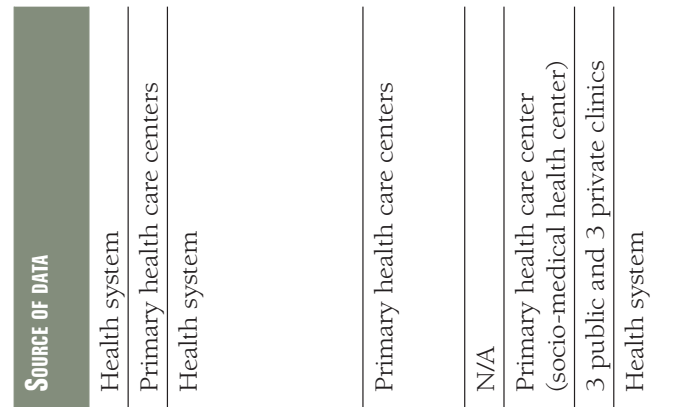

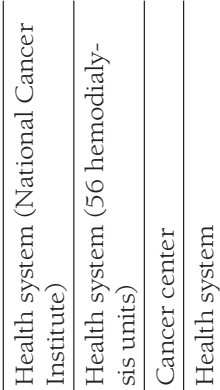

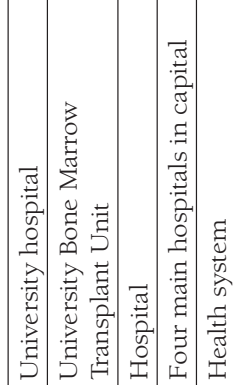

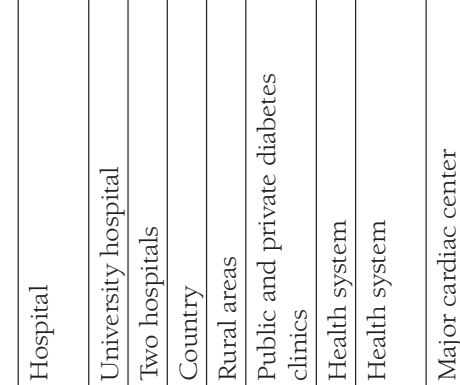

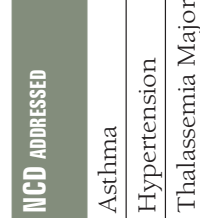

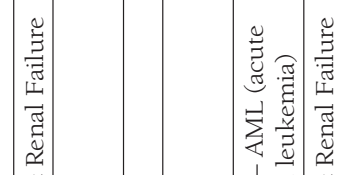

문.

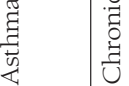

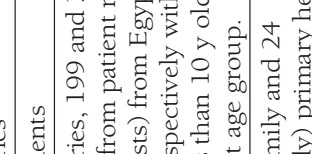

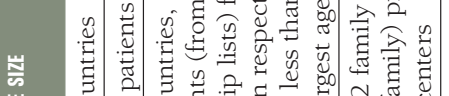

崖 \begin{tabular}{ccc}
0 & $\infty$ \\
0 & 0 \\
$\circ$ & $\infty$ \\
\hdashline & $m$ \\
\hline
\end{tabular}

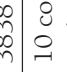

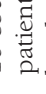




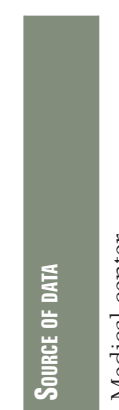

啇

는

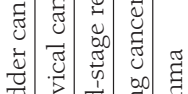

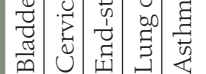

$\stackrel{?}{\stackrel{7}{*}}$

in

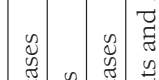

崖

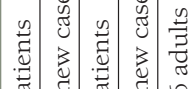

竞

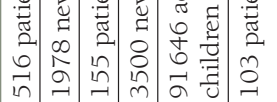

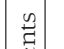

幽

泀泀

(1)

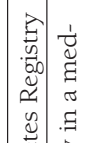

离

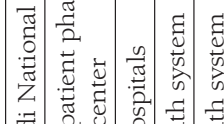

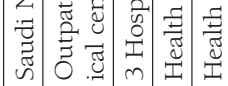

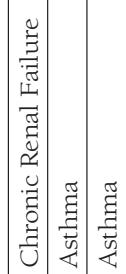

चี

苟 :

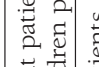

莗

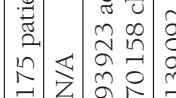

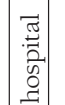

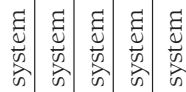
च चี

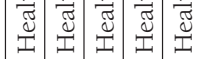

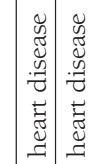

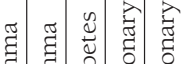
晏

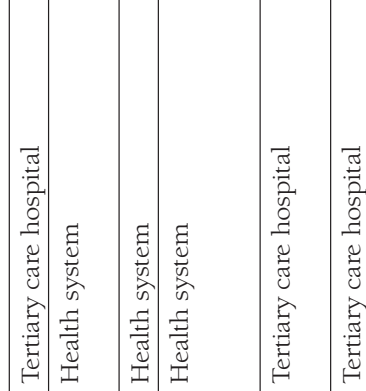

|

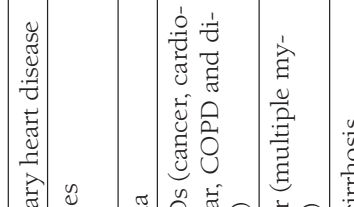

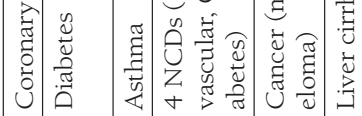

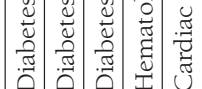

苛

.

(2)

$\overrightarrow{8}$

仓े

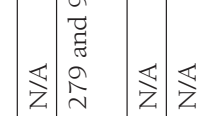

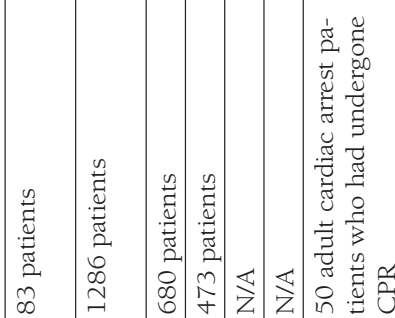

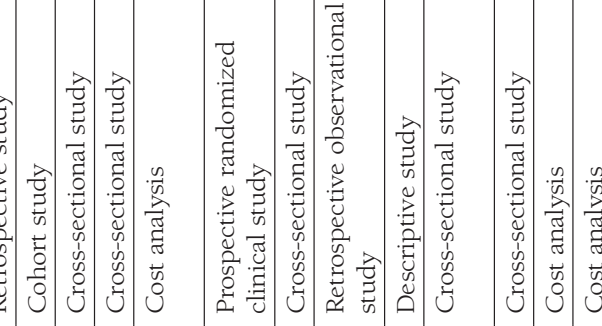

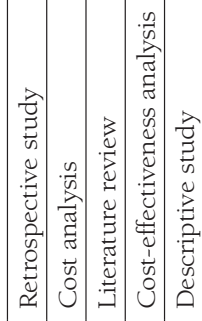

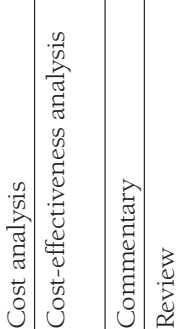

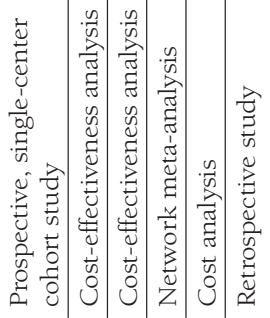

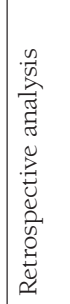

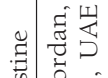

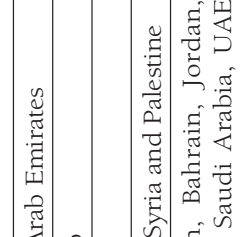

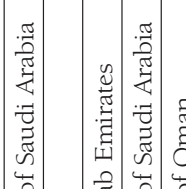

낭

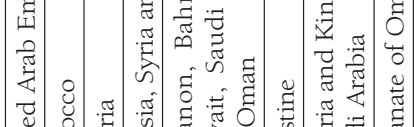

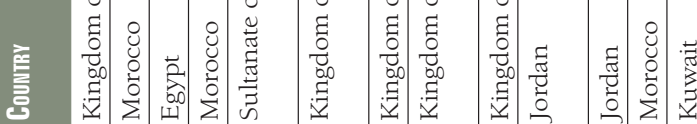

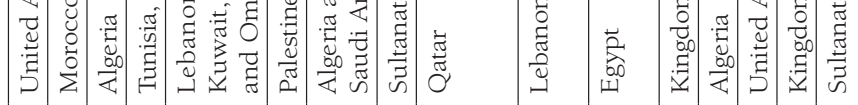

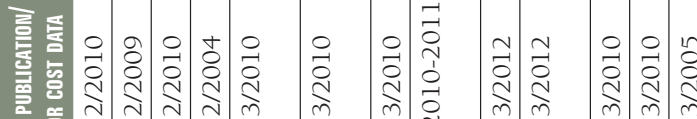

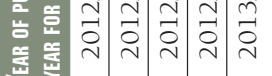

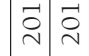

㲾

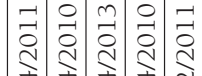

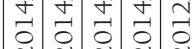

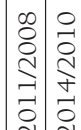

年

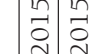

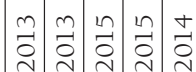

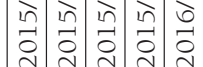

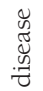

彥

בั

है के

च

¿

1 क्ष

ชิ

$\sqrt{5}$

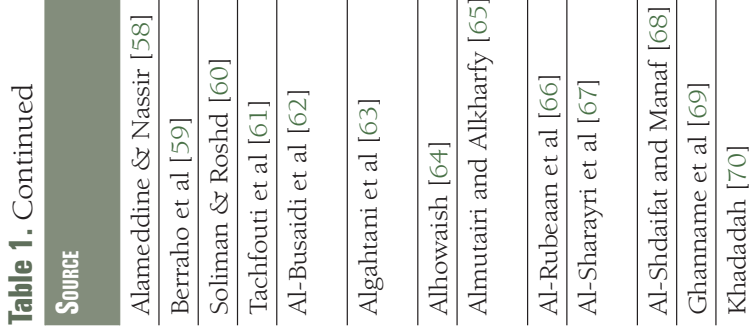

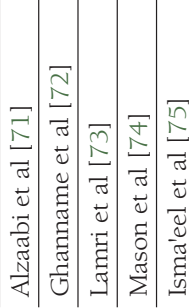

\section{疋}

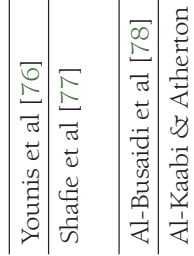

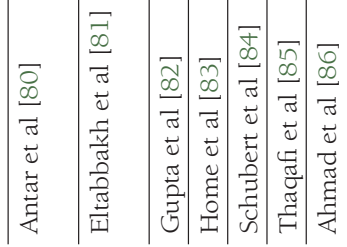

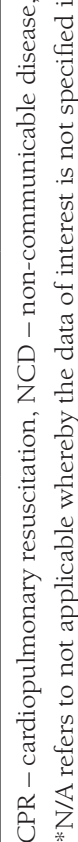

证

की

हี 음

焉 $\frac{\bar{g}}{3}$

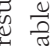

छิ

ह

茴

迹

芯 


\section{Overview of included studies}

The reviewed articles covered most of the Arab region, yet no data was available from 6 of the 22 Arab countries, namely Iraq, Somalia, Libya, Mauritania, Djibouti and Comoros. The majority of studies $(n=27)$ originated from high-income Arab countries, while 19 were conducted in lower-middle income and 12 were from upper-middle income Arab countries. This reflected GDP variation across the reviewed articles. Most studies were conducted in the Kingdom of Saudi Arabia ( $n=15)$, Egypt $(n=8)$ and Jordan $(n=7)$ whereas 5 studies were conducted in multiple countries (Table 1 ). Included studies were mainly observational with retrospective or prospective design, few other studies were modeling, reviews, systematic reviews, meta-analyses, commentaries and cost analyses. In 30 studies, the setting represented was the health system. The remaining studies sampled eligible participants from hospitals $(n=15)$, medical centers $(n=5)$, primary health care centers $(n=3)$ and private and public clinics $(n=2)$ (Table 1$)$.

The most frequently studied NCD was diabetes $(n=18)$ whereas chronic respiratory diseases (mainly asthma, $\mathrm{n}=9$ ) and cancer were each analyzed in 11 studies. Twelve studies focused on cost associated with management of cardiovascular diseases while 7 studies focused on other NCDs mainly chronic renal failure (Table 1). Only one study addressed the four NCDs together.

All of the included studies reported direct medical costs associated with the management of the four major non-communicable diseases in the Arab region. Some studies $(n=15)$ also included indirect costs such as loss of productivity and premature death. While only one article described direct non-medical costs that are not directly related to medical services such as transportation. (Table 4).

Cost data collected through surveys represented the most commonly used data source $(n=19)$ while 12 studies relied on data retrieved from health information systems of ministries, hospitals and insurance companies followed by prior estimates published in the literature, which is represented as electronic database $(n=12)$ in Table 5. Medical records were used in eight studies and a data source was not applicable for the component costs of one study. Some studies included several cost components and data sources without giving a clear description of which data sources were used for particular components.

Among the 55 studies included, 23 (42\%) studies described the patient's perspective and 21 (38\%) studies described the provider's perspective in estimating the costs highlighting that the majority of the studies focused on the costs that fall on either patients or health care institutions providing health services. Eight studies looked at the governmental costs associated with NCDs. The remaining studies $(n=8)$ described the societal level costs.

Although most of the studies did not clearly indicate the costing approach used, the overall aim of the cost analysis and the sources of data assisted in determining the costing approaches followed. Most of the studies $(n=36)$ estimated the costs using a bottom up approach or micro-costing, while only nine studies relied on a top-down approach or gross-costing in their measurements. Only one study reported using both approaches, while identifying the costing approach was not applicable in seven of the included studies.

\section{Quality of the included studies}

The majority of the studies were appointed a quality score ( 34 of the 55 included studies). In the studies where a quality score was not assigned, the study design and methodology made quality assessment not feasible. The median quality score over all the studies was three out of nine (interquartile range 2-4). Two thirds of the eligible and scored studies scored three points or less, showing that most of the studies were of low to very low quality.

\section{Cardiovascular diseases}

As part of a cost-effectiveness analysis by Mason et al (2014) for the implementation of salt reduction policies [74], health care cost of coronary heart diseases (CHD) in Palestine was estimated (Table 2). The calculation of health care cost of CHDs incorporated standardized unit cost per patient for a number of CHD conditions, namely, acute myocardial infractions (AMI), secondary prevention following AMI, unstable angina, chronic heart failure (treated in a hospital setting, or in the community), and hypertension [74]. Healthcare cost of coronary heart diseases in Palestine was estimated to be US\$ 354719519 [74] (Table 2).

A second study from Palestine also quantified costs associated with treating cardiovascular diseases; more specifically, the study estimated total cost of the cardiac catheterization unit in a major governmental hospital in Palestine as part of cost-volume-profit analysis [76]. Total cost calculations included fixed costs 


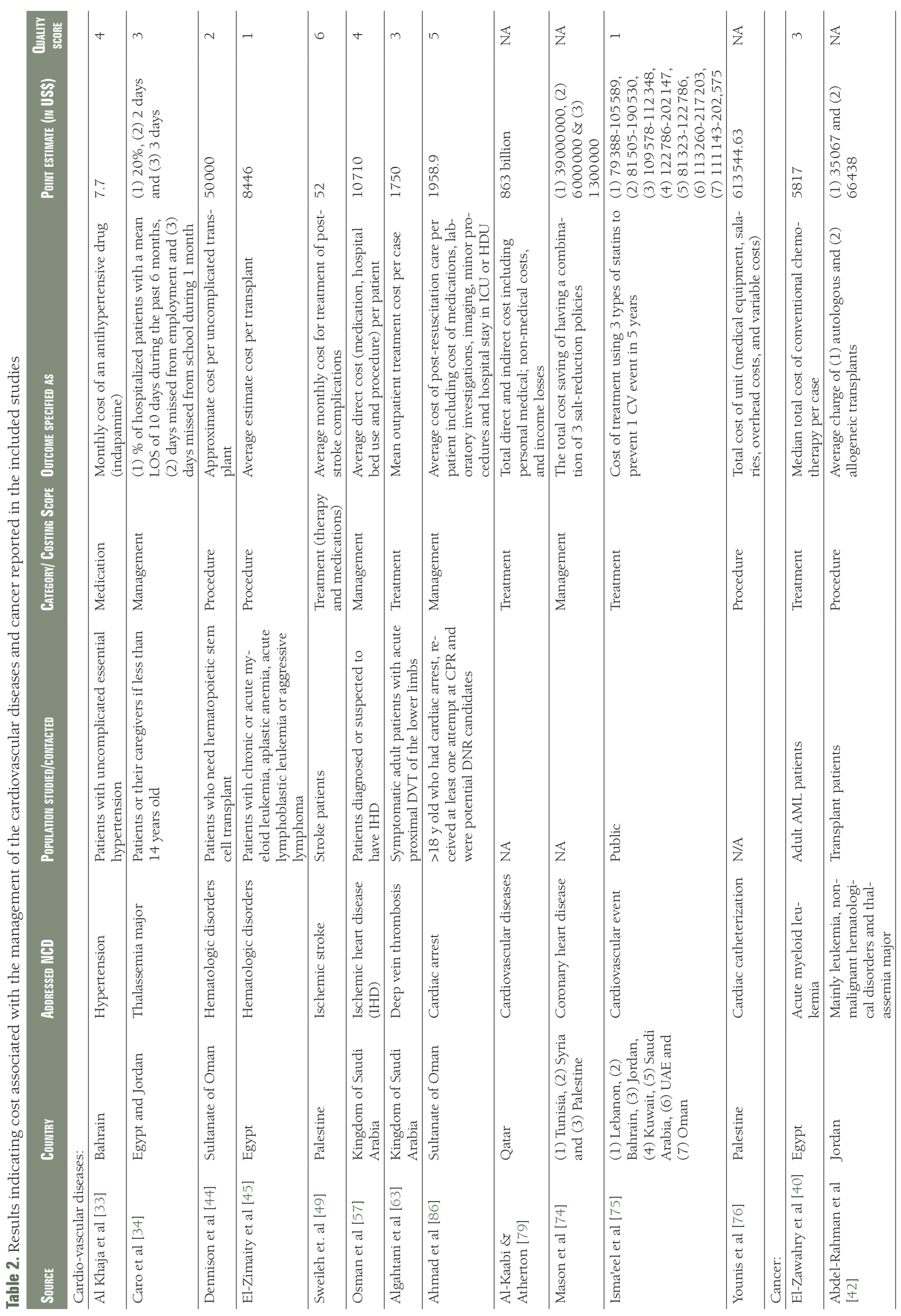




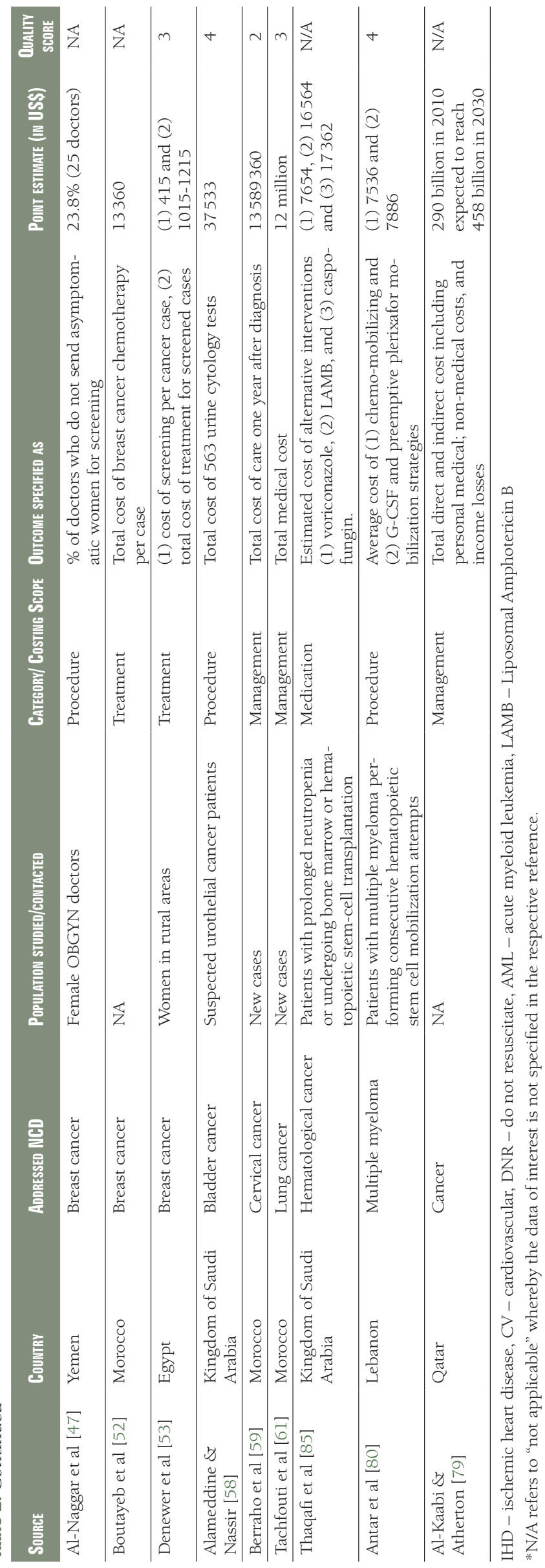

of medical equipment, furniture and other equipment, staff salaries, and overhead costs, and variable costs related to type of patient diagnosis, and respective procedures. Total unit cost was found to be US\$ 613544.63 , with greatest costs attributed to variable costs of catheterization unit [76].

Isma'eel et al (2011) estimated the cost to the public of preventing a single cardiovascular event focusing on statins in seven Arabic countries and those are Lebanon, Bahrain, Jordan, Kuwait, Saudi Arabia, UAE and Oman [75]. The study compared cost based on defined daily dose, and compared costs of using one of three different statins for prevention. For instance, in Lebanon, the cost to the public was found to range between US\$ 79388 and US\$ 105589 , depending on the statin used for treatment. In Bahrain, the cost to the public to prevent one cardiovascular event using statins ranged between US\$ 81505 and US\$ 190530 . Conversely, in Kuwait, the estimated cost to the public ranged between US\$ 122786 and US\$ 202 147, depending on the statin used for treatment [75].

\section{Cancer}

Three studies quantified total costs associated with treating or managing cancer (breast, lung, or cervical) to Moroccan health care authorities for up to one year after diagnosis (Table 2). Boutayeb et al (2010) estimated total cost of breast cancer treatment by chemotherapy for patients in early stages of breast cancer to be between US\$ 13300000 and US\$28600 000, based on international guidelines [52]. The upper bound estimation assumes all new cancer cases are treated. These costs were calculated by estimating the number of women in Morocco with breast cancer, and took into consideration alternative treatment protocols, per unit and per whole cycle [52]. Tachfouti et al (2012) conducted similar calculations to quantify direct costs of managing lung cancer in Morocco [61]. Taking into consideration the incidence of lung cancer, by stage, in the Moroccan population, also, taking into consideration treatment protocols as per international guidelines for each stage of lung cancer, the authors estimated that total medical costs of lung cancer are approximately US\$12000000 [61]. Berraho et al (2012) used a similar methodology to Tachfouti et al (2012) to calculate total costs of managing cervical cancer in Morocco $[59,61]$. After estimating the incidence of cervical cancer cases, by stage, in the Moroccan population, and costs of management based on whole-cycle sets, the authors estimated total cost of cervical cancer care to be US $\$ 13589360$.

\section{Diabetes mellitus}

Elrayah et al (2005) calculated annual direct costs to diabetic children attending public and private diabetes clinics in Sudan, that were associated with controlling diabetes mellitus type 1 [54] (Table 3). The authors estimated the annual direct cost per diabetic child to be 


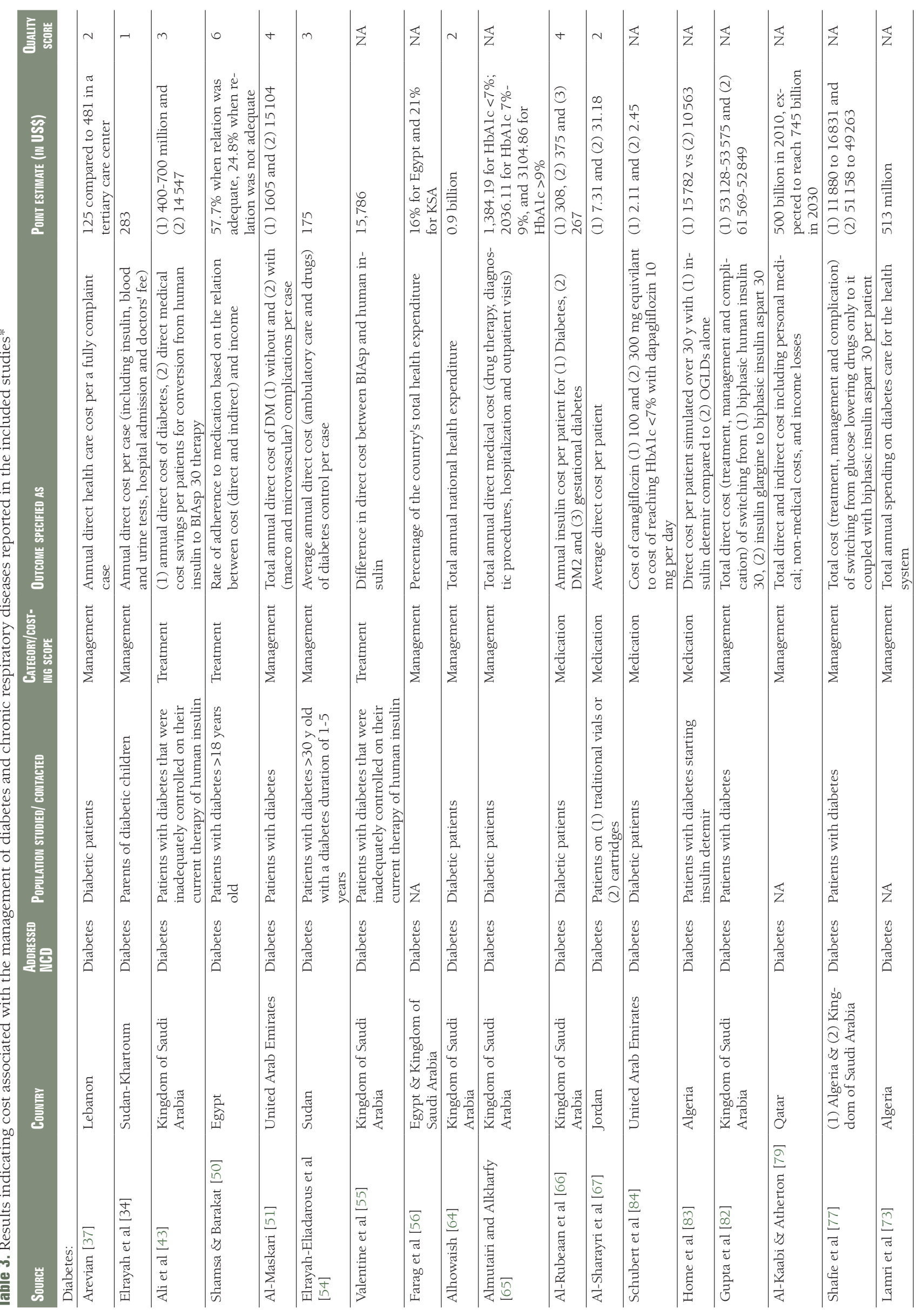




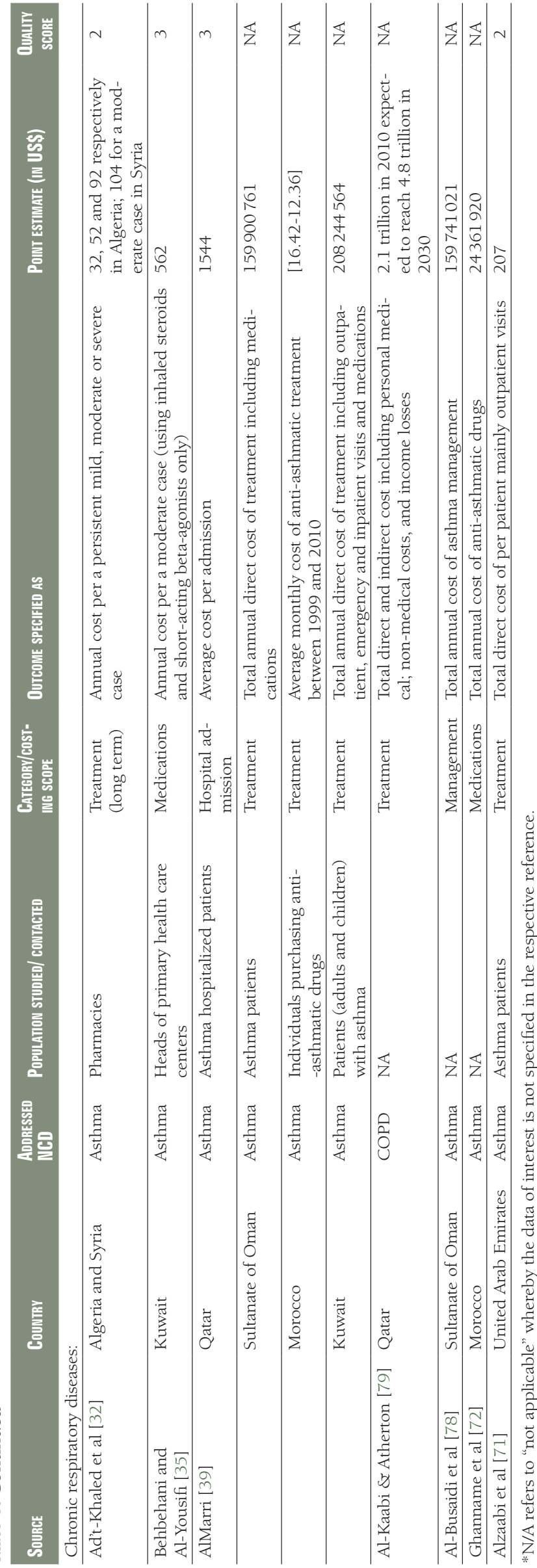

US $\$ 283$ including costs of insulin, blood and urine tests and hospital admission and doctors' fees. In 2010, the authors conducted a survey to determine out-of-pocket contributions made by patients with diabetes mellitus type 2 on ambulatory care and medications used to control diabetes, and found that annual direct cost per patient was approximately US $\$ 175$. Patients aged 65 years and older made the greatest out-of-pocket contributions; furthermore, patients receiving ambulatory outpatient care at private clinics paid significantly more for clinic visits compared to patients receiving care at public facilities [54].

A smaller scale study from Lebanon [37], conducted at a primary health care center in Beirut, estimated the direct cost of treating a fully compliant patient with diabetes mellitus type 2 to be US $\$ 125$ (Table 3). Direct cost calculations included costs of physician services, laboratory tests, drugs, inpatient care and emergency visits. Cost per patient attending the primary health care center was found to be lower than the estimated direct health care cost of US\$ 481 for a fully compliant diabetes mellitus type 2 patient attending private clinics at a tertiary medical care center in Lebanon.

In a national cross-sectional survey conducted in Saudi Arabia, Alhowaish (2013) estimated the total annual national health expenditure to be US\$ 0.9 billion, which represents around $21 \%$ of the country's total health expenditure $[56,64]$. This figure is not restricted to only direct medical costs associated with management of diabetes in Saudi Arabia. Another study examined annual direct costs of diabetes at the national level and estimated the amount to be between US\$ 400 to 700 million [43]. In comparison, a study from Qatar showed that direct and indirect medical cost of diabetes management, including personal medical expenses, nonmedical costs and income losses reached US $\$ 500$ billion in 2010 and projections showed an expected rise to US $\$ 745$ billion in 2030 due to several factors [79].

\section{Asthma}

Two studies from Kuwait quantified costs associated with treating asthma (Table 3). The first determined the annual cost of asthma medications, based on severity, while the second evaluated direct costs of treating asthma at the national level and determined direct costs associated with emergency department visits, outpatient clinic visits, and asthma medications [35,70]. Behbehani $\&$ Al-Yousifi (2003) calculated that the annual cost of a year's supply of medications for a moderate asthma case was equivalent to US\$562; cost of medications for a severe persistent case of asthma was found to be almost equivalent to the monthly salary of a nurse working in Kuwait [35]. Khadadah (2013), in a more recent study, estimated the annual cost of treating asthma cases among Kuwaiti nationals attending government health care facilities in Kuwait [70]. The estimated cost of treating asthma cases among Kuwaiti nationals was 
Table 4. Results indicating cost associated with the management of other NCDs reported in the included studies

\begin{tabular}{|c|c|c|c|c|c|c|c|}
\hline Source & Countiy & $\begin{array}{l}\text { ADDRESSED } \\
\text { NCD }\end{array}$ & $\begin{array}{l}\text { Population STUDied / } \\
\text { CONTACTED }\end{array}$ & $\begin{array}{l}\text { Category/ } \\
\text { Costing Scope }\end{array}$ & OUtCOME SPECIFIED AS & Point estimate (In US\$) & $\begin{array}{l}\text { QuALTY } \\
\text { SCORE }\end{array}$ \\
\hline $\begin{array}{l}\text { Shaheen and Al } \\
\text { Khader [36] }\end{array}$ & $\begin{array}{l}\text { Kingdom of } \\
\text { Saudi Arabia }\end{array}$ & $\begin{array}{l}\text { Chronic re- } \\
\text { nal failure }\end{array}$ & NA & Procedure & $\begin{array}{l}\text { Annual cost incurred toward main- } \\
\text { tenance hemodialysis }\end{array}$ & 19400 & NA \\
\hline $\begin{array}{l}\text { Batieha et al } \\
{[41]}\end{array}$ & Jordan & $\begin{array}{l}\text { Chronic re- } \\
\text { nal failure }\end{array}$ & $\begin{array}{l}\text { Patients on he- } \\
\text { modialysis }\end{array}$ & Procedure & $\begin{array}{l}\text { Total annual cost of hemodialysis } \\
\text { including hemodialysis sessions, } \\
\text { medications and investigations, } \\
\text { admissions and arterial access }\end{array}$ & 29715553 & 4 \\
\hline $\begin{array}{l}\text { Strzelczyk et al } \\
{[46]}\end{array}$ & $\begin{array}{l}\text { Sultanate of } \\
\text { Oman }\end{array}$ & Epilepsy & $\begin{array}{l}\text { Patients aged } \\
>13 \text { years old }\end{array}$ & Management & $\%$ attributed to inpatient admission & $52 \%$ & NA \\
\hline Sabry et al [48] & $\begin{array}{l}\text { Kingdom of } \\
\text { Saudi Arabia }\end{array}$ & $\begin{array}{l}\text { Chronic re- } \\
\text { nal failure }\end{array}$ & $\begin{array}{l}\text { Adult chronic } \\
\text { renal failure pa- } \\
\text { tients stabilized } \\
\text { on hemodialysis }\end{array}$ & Treatment & $\begin{array}{l}\text { Mean cost of } 6 \text { mo use of (1) } \\
\text { tinzaparin sodium per patient com- } \\
\text { pared to that of ( } 2 \text { ) unfractionated } \\
\text { heparins }\end{array}$ & $\begin{array}{l}\text { (1) } 67.57 \text { and (2) } \\
51.23\end{array}$ & 2 \\
\hline $\begin{array}{l}\text { Soliman \& } \\
\text { Roshd [60] }\end{array}$ & Egypt & $\begin{array}{l}\text { End-stage } \\
\text { renal dis- } \\
\text { ease }\end{array}$ & $\begin{array}{l}\text { Chronic renal } \\
\text { failure patients }\end{array}$ & Management & $\begin{array}{l}\text { (1) annual cost for thrice-week- } \\
\text { ly hemodialysis, ( } 2 \text { cost of CAPD } \\
\text { catheter insertion, (3) annual cost } \\
\text { of } 3 \text { to } 4 \text { fluid exchanges, (4) costs } \\
\text { for pre-transplantation and trans- } \\
\text { plantation procedures, (5) annual } \\
\text { costs for immunosuppressive drugs }\end{array}$ & $\begin{array}{l}\text { (1) } 3250,(2) 150 \text {, } \\
\text { (3) }[4500-6000],(4) \\
6000-7500 \text { and (5) } \\
3250-6000\end{array}$ & 1 \\
\hline $\begin{array}{l}\text { Al-Shdaifat and } \\
\text { Manaf [68] }\end{array}$ & Jordan & $\begin{array}{l}\text { Chronic re- } \\
\text { nal failure }\end{array}$ & $\begin{array}{l}\text { Chronic renal } \\
\text { failure patients }\end{array}$ & Procedure & $\begin{array}{l}\text { (1) total annual cost at } \mathrm{MOH} \text { and } \\
\text { (2) annual cost per patient }\end{array}$ & $\begin{array}{l}\text { (1) } 17.7 \text { million and } \\
\text { (2) } 9976\end{array}$ & 3 \\
\hline $\begin{array}{l}\text { Eltabbakh et al } \\
\text { [81] }\end{array}$ & Egypt & $\begin{array}{l}\text { Liver cir- } \\
\text { rhosis }\end{array}$ & $\begin{array}{l}\text { Liver cirrhosis } \\
\text { patients }\end{array}$ & Procedure & $\begin{array}{l}\text { Annual cost of detecting a treatable } \\
\text { HCC case by (1) ultrasound and ( } 2 \text { ) } \\
\text { by both ultrasound and AFP }\end{array}$ & (1) 560 and (2) 650 & 2 \\
\hline
\end{tabular}

$\mathrm{MOH}$ - Ministry of Health, HCC - Hepatocellular carcinoma, AFP -Alpha-fetoprotein, CAPD - Continuous ambulatory peritoneal dialysis

*N/A refers to "not applicable" whereby the data of interest is not specified in the respective reference.

US\$208244564, with the greatest cost drivers being inpatient hospital stays and emergency department visits, while medications constituted only $7 \%$ of total direct costs of treatment [70].

\section{DISCUSSION}

As NCDs' burden in the Arab region continues to grow, it becomes more necessary to assess the impact (financial and economic) of NCDs on patients and governments. In this review, studies providing quantification of costs associated with NCDs in 22 Arab countries, their treatment, management, or risk factors were included. The review identified and summarized only 55 studies covering the 16-year period (20002016). Costing studies were derived from LMICs like Sudan, Palestine, and Morocco, upper-middle-income countries and HICs, with four studies covering multiple countries in the Arab region [74-76,89]. All four classes of major NCDs [5], including diabetes, asthma, cancer and cardiovascular diseases were evaluated, and costs were determined for treatment or management of diseases, at the societal, governmental, provider, or patient level.

The studies were classified by costing variables such as costing approach, costing perspective, types of costs, and sources of information, although many of the studies did not indicate the method of costing used, nor specify the types of costs included. Furthermore, there was a large variation in the methods used to quantify NCDs' costs in these countries. This lack of standardization made it difficult to conduct any type of cross-country, intra-country, or international comparisons. Any kind of cross-country comparison was further impeded by a focus, in the majority of identified studies, on treatment or management of only one class or type of NCD, with the exception of one study from Lebanon, which looked at costs of all smoking-related NCDs [89]. Also limiting cross-country and intra-country comparisons was inclusion of only one or a few variables of cost in calculations, with almost no calculations of the costs of NCDs covered in their totality. As such, it was not possible to identify trends in the costs of NCD management for Arab countries. Only three studies from Morocco used similar methodologies to quantify the costs of different classes of cancer to the Moroccan government $[52,59,61]$. These studies were also among the most comprehensive in their calculations, looking at different disease stages, and considering the incidence of the disease, and the different treatment modalities $[52,59,61]$. Even in the latter case, the heterogeneity in the cost calculation did not allow for trend identification. Nevertheless, the use of a semi-standardized method to quantify the direct costs of the different types of cancer in Morocco had its 
Table 5. Results indicating costing approach, costing perspective, type of costs and sources of information associated with the management of the NCDs reported in the included studies*

\begin{tabular}{|c|c|c|c|c|c|}
\hline Source & YeAR & Costing approach & Costing Perspective & TYPE OF COSTS & SOURCES OF INFORMATION* \\
\hline Ad't-Khaled et al [32] & 2000 & Bottom up & Governmental & Direct medical and indirect & Survey \\
\hline Al Khaja et al [33] & 2001 & Bottom up & Societal & Direct medical & Survey \\
\hline Caro et al [34] & 2002 & N/A & Patient & Direct medical and indirect & Survey \\
\hline Behbehani and Al-Yousifi [35] & 2003 & Top down & Provider & Direct medical & Survey \\
\hline Shaheen and Al Khader [36] & 2005 & N/A & Governmental & Direct medical & NA \\
\hline Arevian [37] & 2005 & N/A & Provider & Direct medical and indirect & Medical record \\
\hline Elrayah et al [38] & 2005 & Bottom up & Provider & Direct medical and indirect & Survey \\
\hline Al Marri [39] & 2006 & Bottom up & Provider & Direct medical & Health information system \\
\hline El-Zawahry et al [40] & 2007 & Bottom up & Patient & Direct medical & Medical record \\
\hline Batieha et al [41] & 2007 & Bottom up & Patient & Direct medical & Survey \\
\hline Abdel-Rahman et al [42] & 2008 & Bottom up & Provider & Direct medical & Medical record \\
\hline Ali et al [43] & 2008 & Bottom up & Provider & Direct and indirect medical cost & Survey \\
\hline Dennison et al [44] & 2008 & Top down & Provider & Direct medical & Medical record \\
\hline El-Zimaity et al [45] & 2008 & N/A & Patient & Direct medical & Medical record \\
\hline Strzelczyk et al [46] & 2008 & Bottom up & Patient & Direct medical and indirect & Electronic databases \\
\hline Al-Naggar et al [47] & 2009 & N/A & Provider & Direct medical & Survey \\
\hline Sabry et al [48] & 2009 & N/A & Patient & Direct medical & Survey \\
\hline Sweileh et. al [49] & 2009 & Bottom up & Patient & Direct medical & Survey \\
\hline Shams \& Barakat [50] & 2010 & N/A & Patient & Direct medical and indirect & Survey \\
\hline Al-Maskari [51] & 2010 & Bottom up & Patient & Direct medical & Survey \\
\hline Boutayeb et al [52] & 2010 & Bottom up & Provider & Direct medical & Secondary data \\
\hline Denewer et al [53] & 2010 & Bottom up & Patient & Direct medical & Survey \\
\hline Elrayah-Eliadarous et al [54] & 2010 & Top down & Patient & Direct medical & Survey \\
\hline Valentine et al [55] & 2010 & Bottom up & Provider & Direct medical & Electronic databases \\
\hline Farag et al [56] & 2011 & Bottom up & Provider & Direct medical & Electronic databases \\
\hline Osman et al [57] & 2011 & Bottom up & Provider & Direct medical & Medical record \\
\hline Alameddine \& Nassir [58] & 2012 & Top down & Provider & Direct medical & Medical record \\
\hline Berraho et al [59] & 2012 & Bottom up & Patient & Direct medical & Health information system \\
\hline Soliman \& Roshd [60] & 2012 & Bottom up & Patient & Direct medical & Survey \\
\hline Tachfouti et al [61] & 2012 & Bottom up & Governmental & Direct medical & Health information system \\
\hline Al-Busaidi et al [62] & 2013 & Bottom up & Patient & Direct medical & Electronic databases \\
\hline Algahtani et al [63] & 2013 & Bottom up & Provider & Direct medical & Health information system \\
\hline Alhowaish [64] & 2013 & Top down & Governmental & Direct medical & Health information system \\
\hline Almutairi and Alkharfy [65] & 2013 & Bottom up & Governmental & Direct medical & Health information system \\
\hline Al-Rubeaan et al [66] & 2013 & Bottom up & Governmental & Direct medical & Health information system \\
\hline Al-Sharayri et al [67] & 2013 & Bottom up & Provider & Direct medical & Medical record \\
\hline Al-Shdaifat and Manaf [68] & 2013 & Bottom up and top down & Provider & $\begin{array}{l}\text { Direct medical and nonmedical } \\
\text { and indirect }\end{array}$ & Health information system \\
\hline Ghanname et al [69] & 2013 & Bottom up & Patient & Direct medical & Health information system \\
\hline Khadadah [70] & 2013 & Bottom up & Patient & Direct medical & Survey \\
\hline Alzaabi et al [71] & 2014 & Bottom up & Government & Direct medical & Health information system \\
\hline Ghanname et al [72] & 2014 & Bottom up & Patient & Direct medical & Health information system \\
\hline Lamri et al [73] & 2014 & Top down & Patient & Direct medical and indirect & Electronic databases \\
\hline Mason et al [74] & 2014 & Top down & $\begin{array}{l}\text { Governmental } \\
\text { and Provider }\end{array}$ & Direct medical and indirect & Survey \\
\hline Younis et al [76] & 2011 & N/A & Provider & Direct medical & Health information system \\
\hline Isma'eel et al [75] & 2012 & N/A & Patient & Direct medical & Electronic databases \\
\hline Shafie et al [77] & 2014 & Bottom up & Patient & Direct medical and indirect & Survey \\
\hline Al-Busaidi et al [78] & 2015 & Bottom up & Patient & Direct medical & Electronic databases \\
\hline Al-Kaabi \& Atherton [79] & 2015 & Top down & Societal & Direct medical and indirect & Electronic databases \\
\hline Antar et al [80] & 2015 & Bottom up & Provider & Direct medical & Health information system \\
\hline Eltabbakh et al [81] & 2015 & Bottom up & Patient & Direct medical and indirect & Survey \\
\hline Gupta et al [82] & 2015 & Bottom up & Societal & Direct medical and indirect & Electronic database \\
\hline Home et al [83] & 2015 & Bottom up & Societal & Direct medical and indirect & Electronic database \\
\hline Schubert et al [84] & 2015 & Bottom up & Provider & Direct medical & Electronic database \\
\hline Thaqafi et al [85] & 2015 & Bottom up & Provider & Direct medical & Electronic database \\
\hline Ahmad et al [86] & 016 & Top down & Patient & Direct medical & Health information system \\
\hline
\end{tabular}

*N/A refers to "not applicable" whereby the data of interest is not specified in the respective reference. 
advantages. It allowed authors to make comparisons with international countries at an individual treatment level, allowed them to make comparisons to the Ministry of Health budgets, both at national and regional levels, and to make comparisons to national income levels [52,59,61]. In all cases, the direct cost of treatment was found to be higher than national budgets, higher than minimum income, but lower than the cost in countries used for comparison, pointing to the heavy burden that cancer treatment places on individuals and governments $[52,59,61]$. Such comprehensive results are useful for governments and decision-makers when allocating budgets and prioritizing funding to health facilities $[52,59,61]$. Yet studies from Morocco failed to look at cancer cost in its totality, and excluded crucial variables like indirect costs, productivity loss, and costs associated with outpatient treatment; therefore, costs obtained are likely an underestimation of the true cost of this NCD $[52,59,61]$. This was a common problem across most studies included in this review. Other methodological limitations identified from the studies included the use of different sampling frames and study designs, due to the epidemiological nature of the majority of the studies included. At the individual country level, instability, data scarcity, and struggling health care (information) systems could explain the variation in the data available to measure costs of NCDs, and thus the varying methodologies used $[90,91]$.

The closest comparison to findings can be extracted from studies conducted in HICs, and from members of Organization for Economic Co-operation and Development (OECD). One such study looked at NCDs' impact on national health expenditure [92]. Researchers found for the majority of included countries that NCDs accounted for at least one third of countries' national health expenditure [92]. This analysis was possible because these countries, mostly OECD members, used a national health account framework for analysis [92]. The availability of standardized data on costs from these countries even made it possible to compare expenditure at two different time periods [92]. Among those studies identified in this review, few considered the time horizon when assessing the costs of NCDs, A systematic review that looked at NCDs' global impact on health care spending and national income, mostly for countries in the American and European WHO regions, found that global health care expenditure on NCDs was increasing with time; furthermore, NCDs were resulting in national income losses [93]. However, this review only included one country from the Arab region [93]. For the most part, other reviews focusing on NCDs' costs to individuals and households suffered from similar methodological limitations as those identified in this review $[29,88]$.

\section{Limitations}

Due to the fact that our study was part of a larger epidemiological approach scoping review, the included studies analyzed in this review are subject to several limitations including absence of a clear definition of costing method used, wide heterogeneity in methods followed to calculate same and different types of cost and variation in case definition. Other limitations are related to missing data on patient characteristics, which could have affected care or cost, sample representativeness like exclusion of individuals not seeking care for financial reasons and uneven geographical distribution. There are also differences between health systems in Arab countries, affecting the allocation of health funds for NCDs' management. These factors did not allow us to pool reported cost estimates, to generalize results or to generate comparisons across studies. Another limitation is the search language used. This review only identified studies published in English, or containing an English abstract or keywords, potentially impacting number of studies identified and included in the review.

\section{CONCLUSIONS}

The burden of NCDs in the Arab region is set to continue growing, conforming to local and global trends. This scoping review on the costs of NCDs in Arab region sheds light on an important issue: although NCDs-related morbidity and mortality continue to rise in all Arab countries across different income levels, data on costing remains limited by this type of evidence's paucity and the generally low quality of studies published in this area. Internationally, NCDs resulted in high health care costs for governments and in great out-of-pocket and catastrophic health expenditures for households. Still, global findings and trends regarding NCDs raises questions of representativeness when inferring about applicability in the local and regional context. Moreover, even at international levels, questions persist concerning methodologies used for inferring costs at the national level.

Furthermore, although this review represents the most comprehensive to-date assessment of studies in the region directly quantifying the costs of NCDs, it remains restricted by the paucity of evidence and the 
generally low to very-low quality of included studies. Hence, if decisions are to be made based on available rough estimates, resources might be used inefficiently.

This research represents a foundational step for policymakers in need of evidence when managing the financial burden of NCDs in future reforms. There is also a need for future studies, of improved and harmonized methodology, from the Arab region on the cost management of NCDs and their growing financial impact at household and governmental levels.

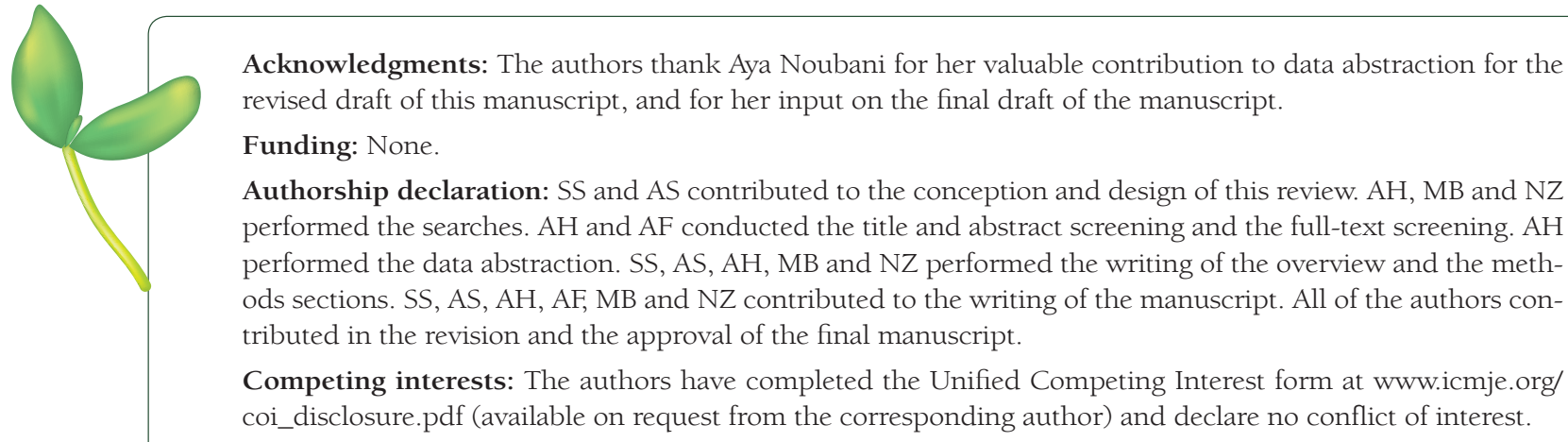

1 Lozano R, Naghavi M, Foreman K, Lim S, Shibuya K, Aboyans V, et al. Global and regional mortality from 235 causes of death for 20 age groups in 1990 and 2010: a systematic analysis for the Global Burden of Disease Study 2010. Lancet. 2012;380:2095-128. Medline:23245604 doi:10.1016/S0140-6736(12)61728-0

2 Mathers CD, Loncar D. Projections of global mortality and burden of disease from 2002 to 2030. PLoS Med. 2006;3:e442. Medline:17132052 doi:10.1371/journal.pmed.0030442

3 World Health Organization. Projections of mortality and causes of death, 2015 and 2030. Geneva: World Health Organization; 2014.

4 Boutayeb A, Boutayeb S. The burden of non communicable diseases in developing countries. Int J Equity Health. $2005 ; 4: 2$. Medline:15651987 doi:10.1186/1475-9276-4-2

5 World Health Organization. Global status report on noncommunicable diseases 2014. Geneva: World Health Organization; 2014.

6 World Health Organization. Global health estimates: Deaths by cause, age, sex and country, 2000-2012. Geneva: World Health Organization; 2014.

7 Low WY. The threat of noncommunicable diseases in South Asia. Asia Pac J Public Health. 2016;28:4S-5S. Medline:26712892

8 Rahim HFA, Sibai A, Khader Y, Hwalla N, Fadhil I, Alsiyabi H, et al. Non-communicable diseases in the Arab world. Lancet. 2014;383:356-67. Medline:24452044 doi:10.1016/S0140-6736(13)62383-1

9 Sibai AM, Fletcher A, Hills M, Campbell O. Non-communicable disease mortality rates using the verbal autopsy in a cohort of middle aged and older populations in Beirut during wartime, 1983-93. J Epidemiol Community Health. 2001; 55:271-6. Medline:11238583 doi:10.1136/jech.55.4.271

10 Sibai A, Tohme R, Mahfoud Z, Chaaya M, Hwalla N. Non-communicable diseases and behavioral risk factor survey. comparison of estimates based on cell phone interviews with face to face interviews. MOPH. 2009. Available: https://www. moph.gov.lb/DynamicPages/download_file/563. Accessed: 23 March 2017.

11 Boutayeb A, Boutayeb S, Boutayeb W. Multi-morbidity of non communicable diseases and equity in WHO Eastern Mediterranean countries. Int J Equity Health. 2013;12:60. Medline:23961989 doi:10.1186/1475-9276-12-60

12 World Health Organization. Noncommunicable diseases progress monitor 2015. 2015. Available: http://apps.who.int/ iris/bitstream/10665/184688/1/9789241509459_eng.pdf

13 World Health Organization. Noncommunicable diseases country profiles 2014. 2014.

14 Hunter DJ, Reddy KS. Noncommunicable diseases. N Engl J Med. 2013;369:1336-43. Medline:24088093 doi:10.1056/ NEJMral109345

15 World Health Organization. First global ministerial conference on healthy lifestyles and noncommunicable disease control. Moscow, the Russian Federation: WHO. 2011.

16 World Health Organization. Noncommunicable diseases, poverty and the development agenda. discussion paper. ECOSOC. 2009. Available: http://www.who.int/nmh/publications/discussion_paper_ncd_en.pdf. Accessed: March 23, 2017

17 Economic Intelligence Unit. The silent epidemic: An economic study of diabetes in developed and developing countries. London: The Economist. Economic Intelligence Unit (EIU); 2007. 
18 Beaglehole R, Bonita R, Alleyne G, Horton R, Li L, Lincoln P, et al. UN High-Level Meeting on Non-Communicable Diseases: addressing four questions. Lancet. 2011;378:449-55. Medline:21665266 doi:10.1016/S0140-6736(11)60879-9

19 Bloom DE, Cafiero ET, Jané-Llopis E, Abrahams-Gessel S, Bloom LR, Fathima S. The global economic burden of non-communicable diseases. Geneva: World Economic Forum; 2011.

20 American Diabetes Association. Economic costs of diabetes in the U.S. in 2012. Diabetes Care. 2013;36:1033-46. Medline:23468086 doi:10.2337/dc12-2625

21 Bahadori K, Doyle-Waters MM, Marra C, Lynd L, Alasaly K, Swiston J, et al. Economic burden of asthma: a systematic review. BMC Pulm Med. 2009;9:24. Medline:19454036 doi:10.1186/1471-2466-9-24

22 Access Economics. The shifting burden of cardiovascular disease in Australia. The National Heart Foundation: Canberra; 2005.

23 Mozaffarian D, Benjamin EJ, Go AS, Arnett DK, Blaha MJ, Cushman M, et al. Heart disease and stroke statistics-2015 update: a report from the American Heart Association. Circulation. 2015;131:e29-322. Medline:25520374

24 Boutayeb A, Boutayeb W, Lamlili MEN, Boutayeb S. Indirect cost of Diabetes in the Arab Region. Int J Diabetol Vasc Disease Res. 2013;1:24-8.

25 Boutayeb A, Boutayeb W, Lamlili MEN, Boutayeb S. Estimation of the direct cost of diabetes in the Arab region. Med J Nutrition Metab. 2014;7:21-32.

26 Joshi A, Mohan K, Grin G, Perin DMP. Burden of Healthcare Utilization and Out-of Pocket Costs Among Individuals with NCDs in an Indian Setting. J Community Health. 2013;38:320-7. Medline:23054417 doi:10.1007/s10900-012-9617-1

27 Mahal A, Karan A, Engelgau M. The economic implications of non-communicable disease for India. Health, Nutrition and Population (HNP) discussion paper. Washington DC: World Bank; 2010.

28 Alwan A, MacLean DR. A review of non-communicable disease in low- and middle-income countries. Int Health. 2009;1:3-9. Medline:24036289 doi:10.1016/j.inhe.2009.02.003

29 Kankeu HT, Saksena P, Xu K, Evans DB. The financial burden from non-communicable diseases in low- and middle-income countries: a literature review. Health Res Policy Syst. 2013;11:31. Medline:23947294 doi:10.1186/1478-450511-31

30 Mulligan J-A, Walker D, Fox-Rushby J. Economic evaluations of non-communicable disease interventions in developing countries: a critical review of the evidence base. Cost Eff Resour Alloc. 2006;4:7. Medline:16584546 doi:10.1186/14787547-4-7

31 Alwan A. Global status report on noncommunicable diseases 2010. Geneva: World Health Organization; 2011.

32 Ad't-Khaled N, Auregan G, Bencharif N, Camara LM, Dagli E, Djankine K, et al. Affordability of inhaled corticosteroids as a potential barrier to treatment of asthma in some developing countries. Int J Tuberc Lung Dis. 2000;4:268-71. Medline: 10751075

33 Jassim al Khaja KA, Sequeira RP, Wahab AW, Mathur VS. Antihypertensive drug prescription trends at the primary health care centres in Bahrain. Pharmacoepidemiol Drug Saf. 2001;10:219-27. Medline:11501335 doi:10.1002/pds.578

34 Caro JJ, Ward A, Green TC, Huybrechts K, Arana A, Wait S, et al. Impact of thalassemia major on patients and their families. Acta Haematol. 2002;107:150-7. Medline:11978936 doi:10.1159/000057633

35 Behbehani NA, Al-Yousifi K. Lack of essential asthma medications in primary care centres in Kuwait. Int J Tuberc Lung Dis. 2003;7:422-5. Medline:12757041

36 Shaheen FA, Al-Khader AA. Preventive strategies of renal failure in the Arab world. Kidney Int Suppl. 2005;98:S37-40. Medline:16108969 doi:10.1111/j.1523-1755.2005.09807.x

37 Arevian M. The significance of a collaborative practice model in delivering care to chronically ill patients: a case study of managing diabetes mellitus in a primary health care center. J Interprof Care. 2005;19:444-51. Medline:16308168 doi: $10.1080 / 13561820500215095$

38 Elrayah H, Eltom M, Bedri A, Belal A, Rosling H, Ostenson CG. Economic burden on families of childhood type 1 diabetes in urban Sudan. Diabetes Res Clin Pract. 2005;70:159-65. Medline:15919129 doi:10.1016/j.diabres.2005.03.034

39 AlMarri MR. Asthma hospitalizations in the state of Qatar: an epidemiologic overview. Ann Allergy Asthma Immunol. 2006;96:311-5. Medline:16498853 doi:10.1016/S1081-1206(10)61241-0

40 El-Zawahry HM, Zeeneldin AA, Samra MA, Mattar MM, El-Gammal MM, Abd El-Samee A, et al. Cost and outcome of treatment of adults with acute myeloid leukemia at the National Cancer Institute-Egypt. J Egypt Natl Canc Inst. 2007; 19:106-13. Medline:19034340

41 Batieha A, Abdallah S, Maghaireh M, Awad Z, Al-Akash N, Batieneh A, et al. Epidemiology and cost of haemodialysis in Jordan. East Mediterr Health J. 2007;13:654-63. Medline:17687839

42 Abdel-Rahman F, Hussein A, Rihani R, Hlalah O, El Taani H, Sharma S, et al. Bone marrow and stem cell transplantation at King Hussein cancer center. Bone Marrow Transplant. 2008;42 Suppl 1:S89-91. Medline:18724314 doi:10.1038/ bmt.2008.126

43 Ali M, White J, Lee CH, Palmer JL, Smith-Palmer J, Fakhoury W, et al. Therapy conversion to biphasic insulin aspart 30 improves long-term outcomes and reduces the costs of type 2 diabetes in Saudi Arabia. J Med Econ. 2008;11:651-70. Medline:19450074 doi:10.3111/13696990802589122

44 Dennison D, Al Kindi S, Pathare A, Daar S, Nusrat N, Ur Rehman J, et al. Hematopoietic stem cell transplantation in Oman. Bone Marrow Transplant. 2008;42 Suppl 1:S109-13. Medline:18724280 doi:10.1038/bmt.2008.131

45 El-Zimaity MM, Hassan EA, Abd El-Wahab SE, Abd El-Ghaffar AA, Mahmoud NA, Elafifi AM, et al. Stem cell transplantation in hematological disorders. A developing country experience-impact of cost considerations. Saudi Med J. 2008; 29:1484-9. Medline:18946578 
46 Strzelczyk A, Reese JP, Dodel R, Hamer HM. Cost of epilepsy: a systematic review. Pharmacoeconomics. 2008;26:46376. Medline:18489198 doi:10.2165/00019053-200826060-00002

47 Al-Naggar RA, Isa ZM, Shah SA, Chen R, Kadir SY. Mammography screening: Female doctors'attitudes and practice in Sana'a, Yemen. Asian Pac J Cancer Prev. 2009;10:743-6. Medline:20104962

48 Sabry A, Taha M, Nada M, Al Fawzan F, Alsaran K. Anticoagulation therapy during haemodialysis: a comparative study between two heparin regimens. Blood Coagul Fibrinolysis. 2009;20:57-62. Medline:20523166 doi:10.1097/MBC.0b013e32831 becof

49 Sweileh WM, Sawalha AF, Zyoud SH, Al-Jabi SW, Abaas MA. Discharge medications among ischemic stroke survivors. J Stroke Cerebrovasc Dis. 2009;18:97-102. Medline:19251184 doi:10.1016/j.jstrokecerebrovasdis.2008.08.005

50 Shams ME, Barakat EA. Measuring the rate of therapeutic adherence among outpatients with T2DM in Egypt. Saudi Pharm J. 2010;18:225-32. Medline:23960731 doi:10.1016/j.jsps.2010.07.004

51 Al-Maskari F, El-Sadig M, Nagelkerke N. Assessment of the direct medical costs of diabetes mellitus and its complications in the United Arab Emirates. BMC Public Health. 2010;10:679. Medline:21059202 doi:10.1186/1471-2458-10-679

52 Boutayeb S, Boutayeb A, Ahbeddou N, Boutayeb W, Ismail E, Tazi M, et al. Estimation of the cost of treatment by chemotherapy for early breast cancer in Morocco. Cost Eff Resour Alloc. 2010;8:16. Medline:20828417 doi:10.1186/14787547-8-16

53 Denewer A, Hussein O, Farouk O, Elnahas W, Khater A, El-Saed A. Cost-effectiveness of clinical breast assessment-based screening in rural Egypt. World J Surg. 2010;34:2204-10. Medline:20533039 doi:10.1007/s00268-010-0620-3

54 Elrayah-Eliadarous H, Yassin K, Eltom M, Abdelrahman S, Wahlstrom R, Ostenson CG. Direct costs for care and glycaemic control in patients with type 2 diabetes in Sudan. Exp Clin Endocrinol Diabetes. 2010;118:220-5. Medline:20140852 doi:10.1055/s-0029-1246216

55 Valentine WJ, Pollock RF, Plun-Favreau J, White J. Systematic review of the cost-effectiveness of biphasic insulin aspart 30 in type 2 diabetes. Curr Med Res Opin. 2010;26:1399-412. Medline:20387997 doi:10.1185/03007991003689381

56 Farag YM, Gaballa MR. Diabesity: an overview of a rising epidemic. Nephrol Dial Transplant. 2011;26:28-35. Medline:21045078 doi:10.1093/ndt/gfq576

57 Osman AM, Alsultan MS, Al-Mutairi MA. The burden of ischemic heart disease at a major cardiac center in Central Saudi Arabia. Saudi Med J. 2011;32:1279-84. Medline:22159384

58 Alameddine M, Nassir A. The influence of urine cytology on our practice. Urol Ann. 2012;4:80-3. Medline:22629001 doi:10.4103/0974-7796.95550

59 Berraho M, Najdi A, Mathoulin-Pelissier S, Salamon R, Nejjari C. Direct costs of cervical cancer management in Morocco. Asian Pac J Cancer Prev. 2012;13:3159-63. Medline:22994727 doi:10.7314/APJCP.2012.13.7.3159

60 Soliman AR, Fathy A, Roshd D. The growing burden of end-stage renal disease in Egypt. Ren Fail. 2012;34:425-8. Medline:22260432 doi:10.3109/0886022X.2011.649671

61 Tachfouti N, Belkacemi Y, Raherison C, Bekkali R, Benider A, Nejjari C. First data on direct costs of lung cancer management in Morocco. Asian Pac J Cancer Prev. 2012;13:1547-51. Medline:22799364 doi:10.7314/APJCP.2012.13.4.1547

62 Al-Busaidi NH, Habibullah Z, Soriano JB. The asthma cost in oman. Sultan Qaboos Univ Med J. 2013;13:218-23. Medline:23862026 doi:10.12816/0003226

63 Algahtani F, Aseri ZA, Aldiab A, Aleem A. Hospital versus home treatment of deep vein thrombosis in a tertiary care hospital in Saudi Arabia: Are we ready? Saudi Pharm J. 2013;21:165-8. Medline:23960831 doi:10.1016/j.jsps.2012.05.008

64 Alhowaish AK. Economic costs of diabetes in Saudi Arabia. J Family Community Med. 2013;20:1-7. Medline:23723724 doi:10.4103/2230-8229.108174

65 Almutairi N, Alkharfy KM. Direct medical cost and glycemic control in type 2 diabetic Saudi patients. Appl Health Econ Health Policy. 2013;11:671-5. Medline:24174262 doi:10.1007/s40258-013-0065-6

66 Al-Rubeaan KA, Youssef AM, Subhani SN, Ahmad NA, Al-Sharqawi AH, Ibrahim HM. A Web-based interactive diabetes registry for health care management and planning in Saudi Arabia. J Med Internet Res. 2013;15:e202. Medline:24025198 doi:10.2196/jmir.2722

67 Al-Sharayri MG, Alsabrah TM, Aljbori TM, Abu-Rumman AE. Insulin vials vs. insulin cartridges: Further cost considerations. Saudi Pharm J. 2013;21:225-7. Medline:23960838 doi:10.1016/j.jsps.2012.07.003

68 Al-Shdaifat EA, Manaf MR. The economic burden of hemodialysis in Jordan. Indian J Med Sci. 2013;67:103-16. Medline:24326762 doi:10.4103/0019-5359.122734

69 Ghanname I, Ahid S, Berrada G, Belaiche A, Hassar M, Cherrah Y. Trends in the use of antiasthmatic medications in Morocco (1999-2010). Springerplus. 2013;2:82. Medline:23519830 doi:10.1186/2193-1801-2-82

70 Khadadah M. The cost of asthma in Kuwait. Med Princ Pract. 2013;22:87-91. Medline:22889866 doi:10.1159/000341154

71 Alzaabi A, Alseiari M, Mahboub B. Economic burden of asthma in Abu Dhabi: a retrospective study. Clinicoecon Outcomes Res. 2014;6:445-50. Medline:25378938 doi:10.2147/CEOR.S68920

72 Ghanname I, Ahid S, Berrada G, Belaiche A, Hassar M, Cherrah Y. Factors influencing anti-asthmatic generic drug consumption in Morocco: 1999-2010. Springerplus. 2014;3:192. Medline:24790832 doi:10.1186/2193-1801-3-192

73 Lamri L, Gripiotis E, Ferrario A. Diabetes in Algeria and challenges for health policy: a literature review of prevalence, cost, management and outcomes of diabetes and its complications. Global Health. 2014;10:11. Medline:24564974 doi: 10.1186/1744-8603-10-11

74 Mason H, Shoaibi A, Ghandour R, O'Flaherty M, Capewell S, Khatib R, et al. A cost effectiveness analysis of salt reduction policies to reduce coronary heart disease in four Eastern Mediterranean countries. PLoS One. 2014;9:e84445. Medline:24409297 doi:10.1371/journal.pone.0084445 
75 Isma'eel H, Mohanna Z, Hamadeh G, Alam E, Badr K, Alam S, et al. The public cost of 3 statins for primary prevention of cardiovascular events in 7 Middle East countries: not all of them can afford it. Int J Cardiol. 2012;155:316-8. Medline:22217486 doi:10.1016/j.ijcard.2011.12.011

76 Younis MZ, Jabr S, Smith PC, Al-Hajeri M, Hartmann M. Cost-volume-profit analysis and expected benefit of health services: a study of cardiac catheterization services. J Health Care Finance. 2011;37:87-100. Medline:21528836

77 Shafie AA, Gupta V, Baabbad R, Hammerby E, Home P. An analysis of the short- and long-term cost-effectiveness of starting biphasic insulin aspart 30 in insulin-naive people with poorly controlled type 2 diabetes. Diabetes Res Clin Pract. 2014;106:319-27. Medline:25305133 doi:10.1016/j.diabres.2014.08.024

78 Al-Busaidi N, Habibulla Z, Bhatnagar M, Al-Lawati N, Al-Mahrouqi Y. The burden of asthma in Oman. Sultan Qaboos Univ Med J. 2015;15:e184-90. Medline:26052450

79 Al-Kaabi SK, Atherton A. Impact of noncommunicable diseases in the State of Qatar. Clinicoecon Outcomes Res. 2015; 7:377-85. Medline:26170702 doi:10.2147/CEOR.S74682

80 Antar A, Otrock ZK, Kharfan-Dabaja MA, Ghaddara HA, Kreidieh N, Mahfouz R, et al. G-CSF plus preemptive plerixafor vs hyperfractionated CY plus G-CSF for autologous stem cell mobilization in multiple myeloma: effectiveness, safety and cost analysis. Bone Marrow Transplant. 2015;50:813-7. Medline:25751646 doi:10.1038/bmt.2015.23

81 Eltabbakh M, Zaghla H, Abdel-Razek W, Elshinnawy H, Ezzat S, Gomaa A, et al. Utility and cost-effectiveness of screening for hepatocellular carcinoma in a resource-limited setting. Med Oncol. 2015;32:432. Medline:25502085 doi:10.1007/ s12032-014-0432-7

82 Gupta V, Baabbad R, Hammerby E, Nikolajsen A, Shafie AA. An analysis of the cost-effectiveness of switching from biphasic human insulin 30, insulin glargine, or neutral protamine Hagedorn to biphasic insulin aspart 30 in people with type 2 diabetes. J Med Econ. 2015;18:263-72. Medline:25426701 doi:10.3111/13696998.2014.991791

83 Home P, Baik SH, Galvez GG, Malek R, Nikolajsen A. An analysis of the cost-effectiveness of starting insulin detemir in insulin-naive people with type 2 diabetes. J Med Econ. 2015;18:230-40. Medline:25407031 doi:10.3111/13696998.2 014.985788

84 Schubert A, Nielsen AT, El Khoury A, Kamal A, Taieb V. Cost of reaching defined HbAlc target using Canagliflozin compared to Dapagliflozin as add-on to Metformin in patients with Type 2 Diabetes Mellitus (T2DM) in the United Arab Emirates (UAE). Value Health. 2015;18:A608. Medline:26533415 doi:10.1016/j.jval.2015.09.2100

85 Thaqafi AA, Xue M, Farahat F, Gao X, Wafy MH, Fahti M, et al. Cost analysis of Voriconazole Versus Liposomal Amphotericin B and Caspofungin for primary therapy of invasive Aspergillosis Among high-risk hematologic cancer patients in Saudi Arabia. Value Health. 2015;18:A667. Medline:26533739 doi:10.1016/j.jval.2015.09.2433

86 Ahmad AS, Mudasser S, Khan MN, Abdoun HN. Outcomes of cardiopulmonary resuscitation and estimation of healthcare costs in potential 'do not resuscitate' cases. Sultan Qaboos Univ Med J. 2016;16:e27-34. Medline:26909209 doi: 10.18295/squmj.2016.16.01.006

87 Wells GA, Shea B, O'Connell D, Peterson J, Welch V, Losos M, et al. The Newcastle-Ottawa Scale (NOS) for assessing the quality of nonrandomised studies in meta-analyses. Ottawa Hospital Research Institute. 2018. Available: http://www. ohri.ca/programs/clinical_epidemiology/oxford.asp. Accessed: 23 March 2017.

88 Jaspers L, Colpani V, Chaker L, van der Lee SJ, Muka T, Imo D, et al. The global impact of non-communicable diseases on households and impoverishment: a systematic review. Eur J Epidemiol. 2015;30:163-88. Medline:25527371 doi: 10.1007/s10654-014-9983-3

89 Salti N, Chaaban J, Naamani N. The economics of tobacco in Lebanon: an estimation of the social costs of tobacco consumption. Subst Use Misuse. 2014;49:735-42. Medline:24328861 doi:10.3109/10826084.2013.863937

90 Akala FA, El-Saharty S. Public-health challenges in the Middle East and North Africa. Lancet. 2006;367:961-4. Medline: 16564342 doi:10.1016/S0140-6736(06)68402-X

91 Ismail SA, McDonald A, Dubois E, Aljohani FG, Coutts AP, Majeed A, et al. Assessing the state of health research in the Eastern Mediterranean Region. J R Soc Med. 2013;106:224-33. Medline:23761582 doi:10.1258/jrsm.2012.120240

92 Garg C, Evans DB. What is the impact of non-communicable diseases on national health expenditures: a synthesis of available data. Discussion Paper No 3. Geneva: World Health Organization; 2011.

93 Muka T, Imo D, Jaspers L, Colpani V, Chaker L, van der Lee SJ, et al. The global impact of non-communicable diseases on healthcare spending and national income: a systematic review. Eur J Epidemiol. 2015;30:251-77. Medline:25595318 doi:10.1007/s10654-014-9984-2 